
\title{
R Research Soure \\ Modeling Human Health Behavior with a New Index That Measures Connectivity
}

Steven L. Bernstein ( $\square$ steven.bernstein@yale.edu )

Yale University School of Medicine

Fangyong Li

Yale University School of Public Health

Fuad Abujarad

Yale University School of Medicine

David Grant

University of Colorado Boulder

Gail D'Onofrio

Yale University School of Medicine

James Dziura

Yale University School of Medicine

Research article

Keywords: health behavior, adherence, abstinence, graph theory, network analysis

Posted Date: October 26th, 2019

DOI: https://doi.org/10.21203/rs.2.16480/v1

License: (c) (i) This work is licensed under a Creative Commons Attribution 4.0 International License.

Read Full License 


\section{SPRINGER NATURE}

\section{Disclosure of potential conflicts of interest}

Authors must disclose all relationships or interests that could have direct or potential influence or impart bias on the work. Although an author may not feel there is any conflict, disclosure of all relationships and interests provides a more complete and transparent process, leading to an accurate and objective assessment of the work. Awareness of real or perceived conflicts of interest is a perspective to which the readers are entitled. This is not meant to imply that a financial relationship with an organization that sponsored the research or compensation received for consultancy work is inappropriate. For examples of potential conflicts of interests that are directly or indirectly related to the research please visit:

http://www.springer.com/gp/authors-editors/journal-author/journal-author-helpdesk/publishing-ethics/14214

All authors of papers submitted to European Journal of Epidemiology must complete this form and disclose any real or perceived conflict of interest.

Please complete one form per author. The corresponding author collects the conflict of interest disclosure forms from all authors. The corresponding author will include a summary statement that reflects what is recorded in the potential conflict of interest disclosure form(s). Please check the Instructions for Authors where to put the statement which may be different dependent on the type of peer review used for the journal. Please note that you cannot save the form once completed. Please print upon completion, sign, and scan to keep a copy for your files. The corresponding author should be prepared to send potential conflict of interest disclosure form if requested during peer review or after publication on behalf of all authors (if applicable).

\section{$\square \quad \mathrm{X}$ I have no potential conflict of interest.}

\begin{tabular}{|l|l|}
\hline Category of disclosure & Description of Interest/Arrangement \\
\hline & \\
\hline & \\
\hline & \\
\hline & \\
\hline & \\
\hline
\end{tabular}

Article title_Modeling Human Health Behavior with a New Index that Measures Connectivity

Manuscript No. (if you know it) EJEP-D-19-00851

Author Name S.Bernstein, F. Li, F. Abujarad, D. Grant, G. D'Onofrio, J.Dziura

$$
\text { Are you the corresponding author? } \square \text { XYes } \square \text { No }
$$

Herewith I confirm that the information provided is accurate. 
Figures

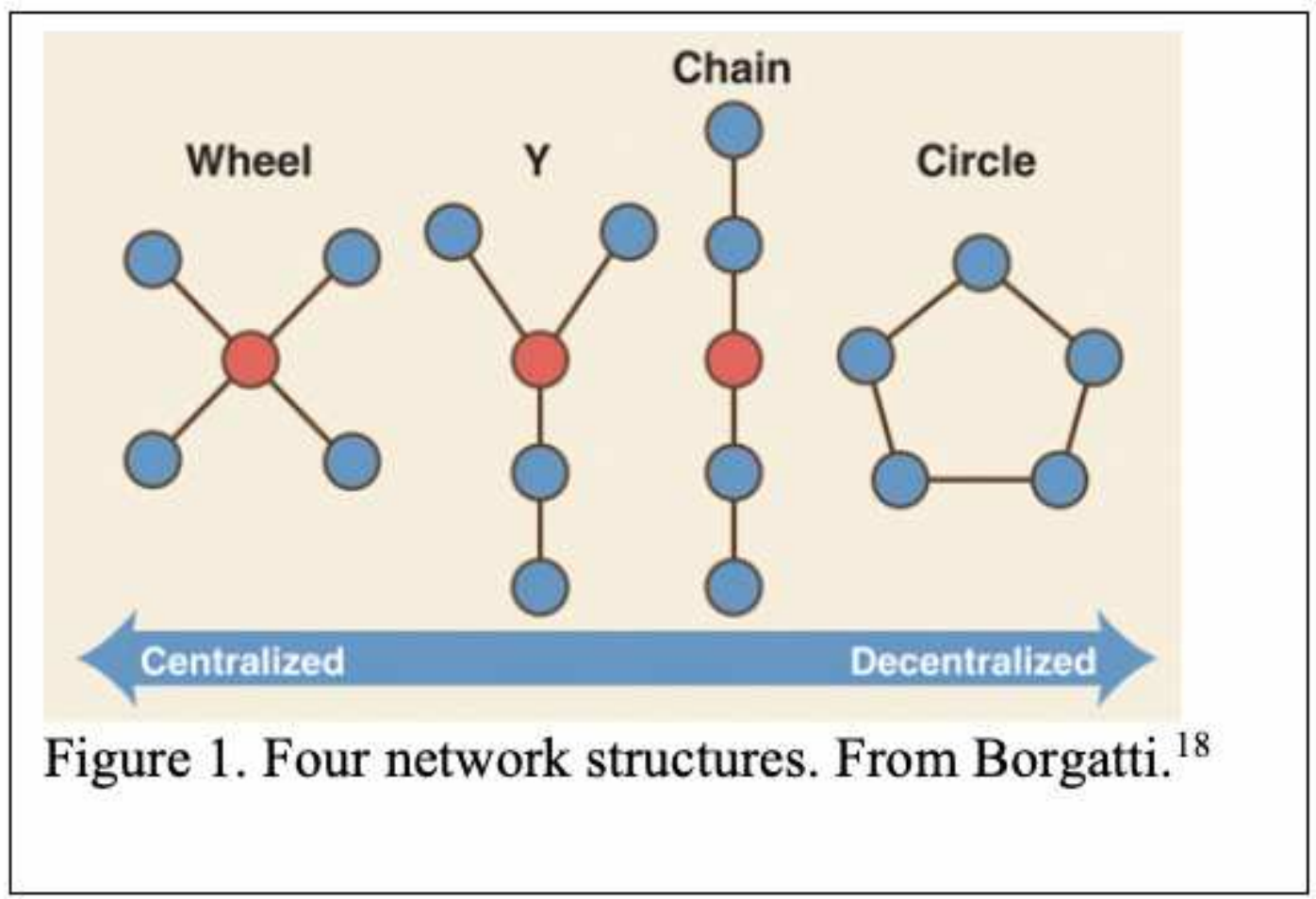

Figure 1 
Fig. 2. Fragment of Framingham social network. From Christakis. ${ }^{19}$

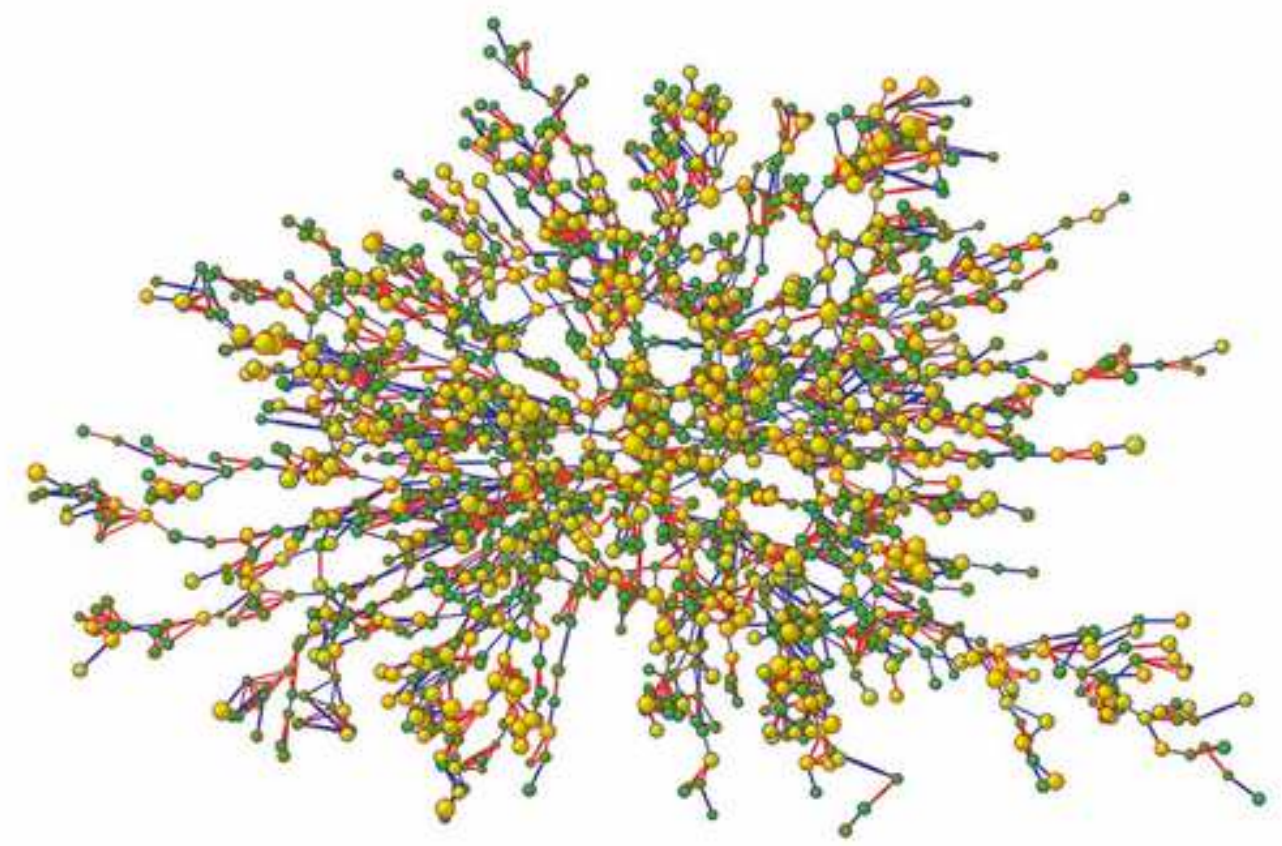

Figure 2 
1)

$\gamma=\left(\left[\left(8^{2}-2^{2}\right) / 10^{2}=(64-4) / 100=60 / 100=0.6\right]+1\right) / 2=\mathbf{0 . 8}$

2)

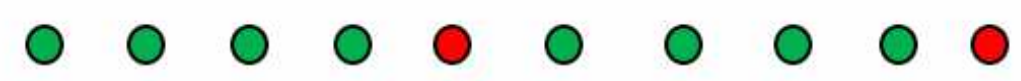

$\gamma=\left(\left[\left(4^{2}-1^{2}+4^{2}-1^{2}\right) / 10^{2}=(16-1+16-1) / 100=30 / 100=0.3\right]+1\right) / 2=\mathbf{0 . 6 5}$

3)

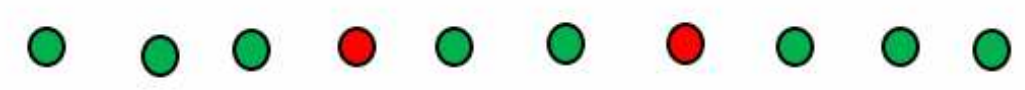

$$
\gamma=\left(\left[\left(3^{2}-1^{2}+2^{2}-1^{2}+3^{2}\right) / 10^{2}=(9-1+4-1+9) / 100=20 / 100=0.2\right]+1\right) / 2=\mathbf{0 . 6}
$$

Figure 3

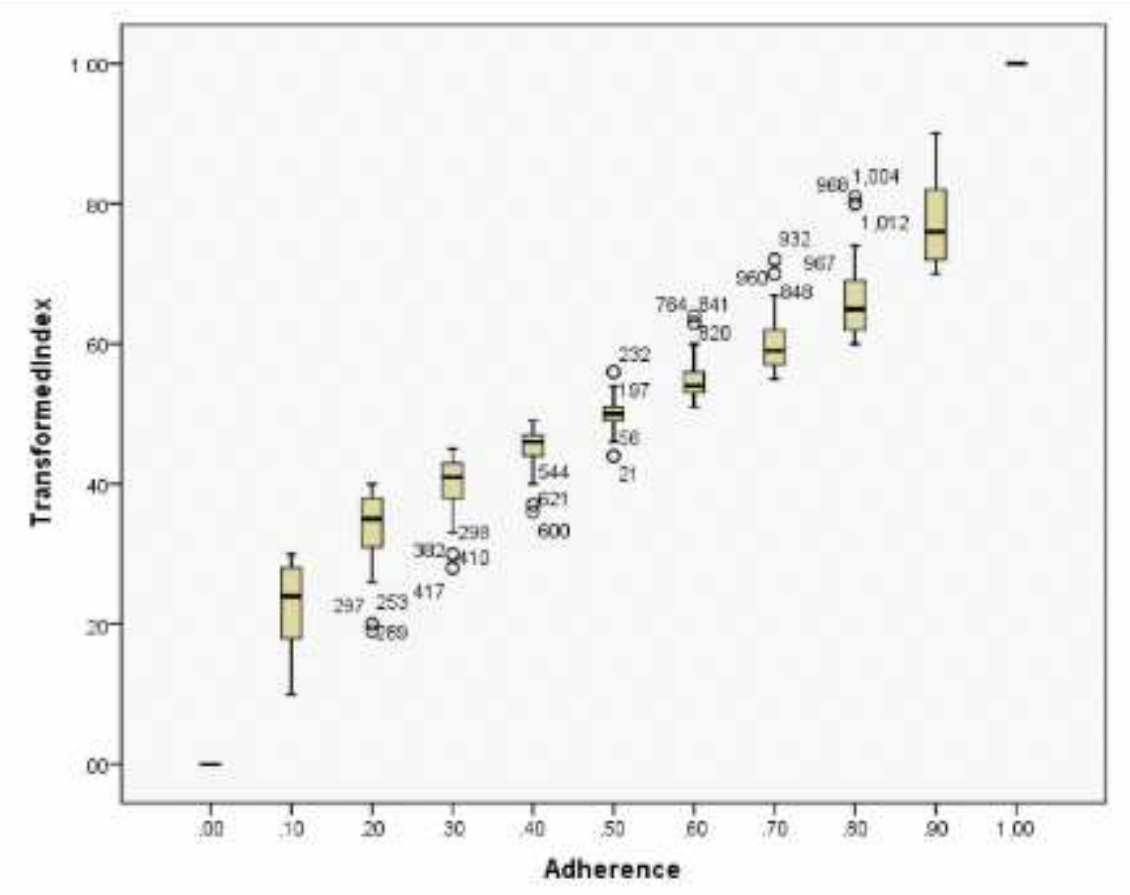

Fig. 4. Box-and-whiskers plots of gamma index range, by decile of adherence, for 10 -dose trial. 


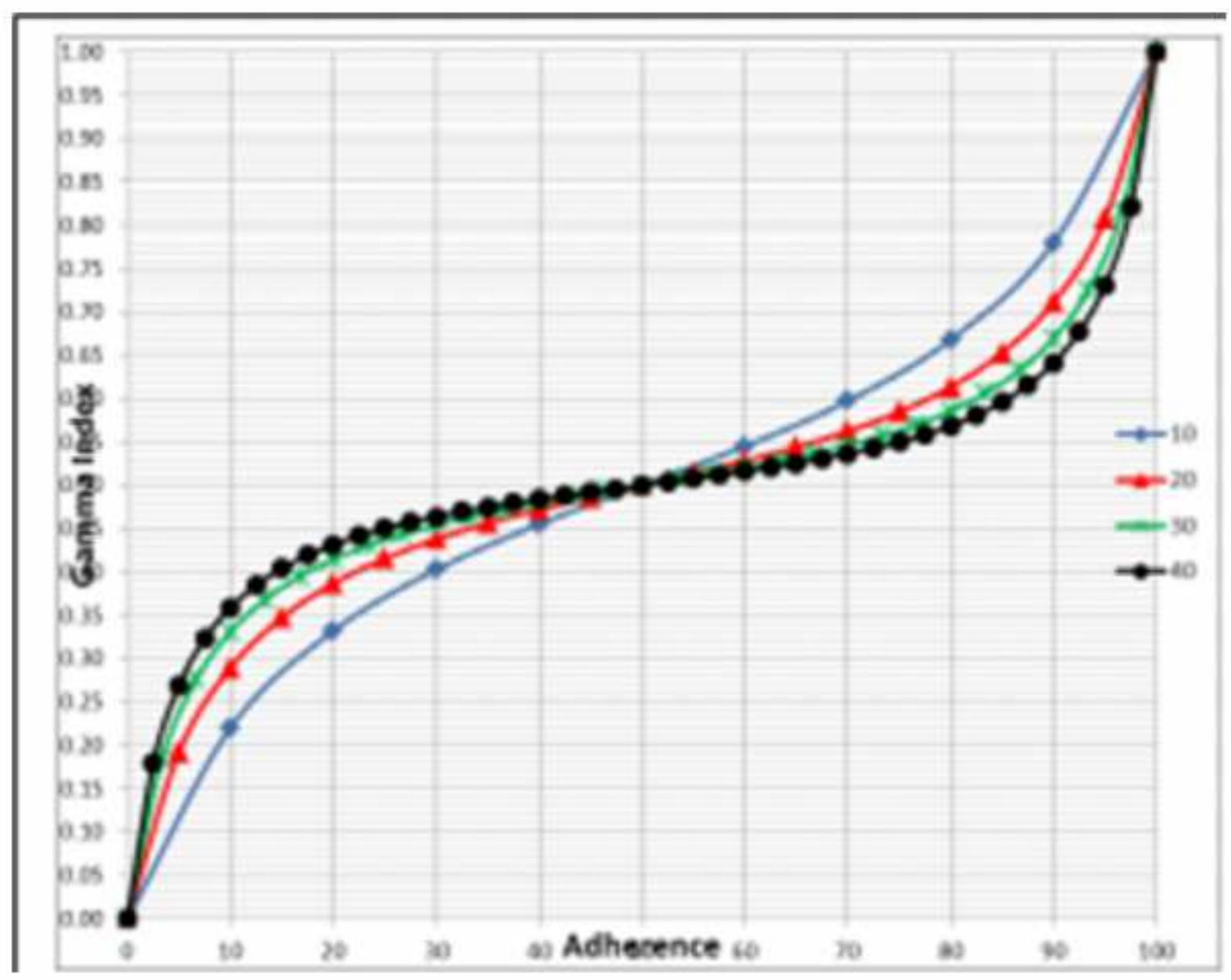

Figure 5 


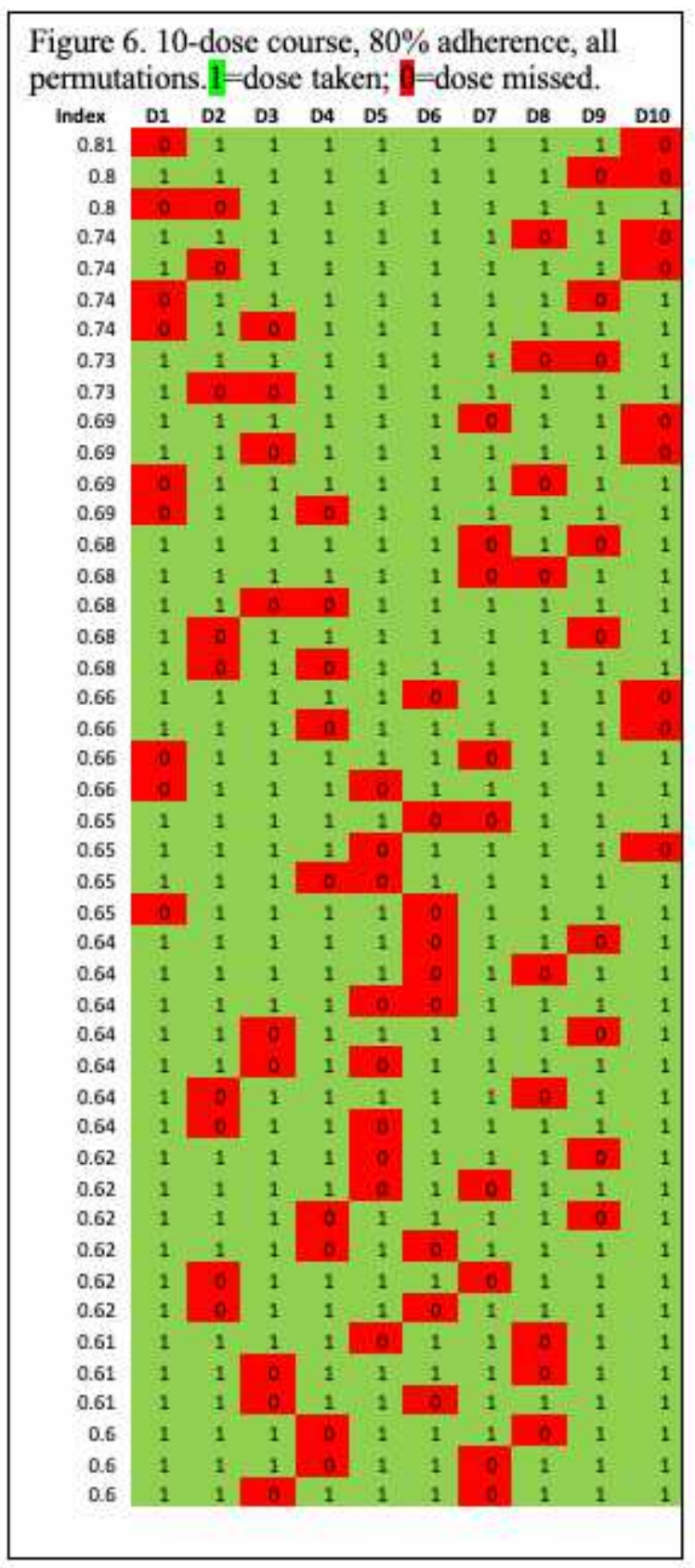

Figure 6

\section{Supplementary Files}

This is a list of supplementary files associated with this preprint. Click to download.

- APPENDIX.docx 